\title{
Revisión del hallazgo de dirhemes califales de Marroquíes Altos (Jaén)
}

Teresa Campos *

\section{INTRODUCCIÓN}

En el presente trabajo hemos realizado una revisión de una publicación anterior sobre el "Hallazgo de Dirhemes Califales de Marroquíes Altos" localizado en la ciudad de Jaén y que en la actualidad se encuentra expuesto en la Sala de Cultura Hispano-Musulmana (Sala 7) del Museo Provincial de dicha ciudad, junto a la vasija donde se encontró '; estando totalmente expuesto al público, excepto seis monedas ${ }^{2}$ que se guardan en los fondos a la espera de su consolidación y restauración.

Este hallazgo se compone de 256 dirhemes califales, con Números de Registro que abarcan desde el 3335 al 359l (ambos inclusive), con una cronología que va desde el año $330 \mathrm{H} / 94 \mathrm{I}$ d.C al $40 \mathrm{IH} / \mathrm{IO}$ IOd.C, estando integrado por piezas de los cinco califas omeyas de al-Andalus y un pequeño grupo que pertenece al califato fatimí de Egipto.

\section{¿UNA REVISIÓN?}

Al encontrarnos con un estudio anterior, hemos considerado primordial abordar este trabajo partiendo de una ratificación y, a veces, comparación con los datos que este estudio ofrecía; fue publicado en el Boletín del Institu- to de Estudios Giennenses, n³2 (Abril/Junio de 1962) y firmado por J.M. Ruiz Asencio. En el mismo se expone que el lugar del hallazgo fue un solar situado entre las calles Millán de Priego y Maestro Bartolomé, con motivo de la apertura de pozos para una cimentación. Huelga decir que la metodología arqueológica fue inexistente.

La idea de llevar a cabo este trabajo realizando una revisión de algo ya estudiado obedece principalmente a dos factores:

A) Utilizar los avances que, especialmente en los últimos 20 años, ha experimentado el campo de la Numismática andalusí, con el fin de realizar un estudio exhaustivo y acorde con las nuevas investigaciones sobre el hallazgo en cuestión.

B) Contrastar la información que nos ofrece la Numismática con la que proviene de la Arqueología y de la Historia. No cabe duda de los avances de estas materias en lo referente a la ciudad de Jaén. Baste citar como ejemplo las excavaciones que se han realizado y que todavía se llevan a cabo en la zona de Marroquíes Bajos y que han arrojado luz sobre el conocimiento de esta ciudad en época islámica.

\footnotetext{
* Universidad de Jaén.

I Recipiente tipo jarra, vidriada, a la que faltan 2 ó 3 cms en su parte superior con un posible pico vertedera.

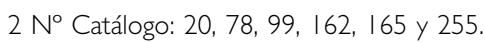


Por todo esto es por lo que estimamos que revisiones y estudios de los materiales que poseemos, a la luz de nuevas teorías, hipótesis y métodos de investigación, sólo pueden llevarnos hacia un mejor conocimiento de una realidad histórica compleja, así como abrir nuevas vías de investigación para el futuro.

Así pues, el tesoro se componía, según Ruiz Asencio, de 270 dirhemes. Sin embargo, el material que se encuentra en el Museo Provincial está integrado por 256 piezas, como ya hemos indicado. De aquí se deduce que existe una diferencia no sólo en el total de las piezas sino también en el número de monedas que se integran dentro de cada período o califa, faltando casualmente algunas piezas de cada uno de los grupos (Tabla I).

\begin{tabular}{|c|c|c|}
\hline \multirow[b]{2}{*}{ CALIFA } & \multicolumn{2}{|c|}{ NÚMERO DE MONEDAS } \\
\hline & ARTÍCULO & MUSEO \\
\hline $\begin{array}{l}\text { ‘Abd al-Raḥmān III } \\
\text { 300H-350H/9 |2-96I d.C }\end{array}$ & 82 & 75 \\
\hline $\begin{array}{l}\text { Al-Hakam II } \\
\text { 350-366H/96I - 1009d.C }\end{array}$ & 44 & 39 \\
\hline $\begin{array}{l}\text { Hišām II } \\
\text { 366-403H/976-10 I3d.C }\end{array}$ & 104 & 89 \\
\hline $\begin{array}{l}\text { Muhammad } \\
\text { 400H/I 009-10d.C }\end{array}$ & 13 & 10 \\
\hline $\begin{array}{l}\text { Sulaymām } \\
\text { 400H/I 009-10d.C }\end{array}$ & 14 & 12 \\
\hline Fatimíes & 27 & 28 \\
\hline TOTAL & 270 & 256 \\
\hline
\end{tabular}

TABLA I.

La fecha de inicio sería el 330H/94 Id.C al ser ésta la primera leída con total seguridad, aunque debemos referirnos a tres dirhemes ${ }^{3}$ no fechados con claridad, que sólo pueden ser encuadrados en la franja cronológica correspondiente a su prefecto de ceca: Sa'id (322330H/933-94 I d.C), por lo que son anteriores. De hecho, Ruiz Asencio da como fecha de inicio la del 322H/933d.C.
La fecha de cierre, tanto en el artículo de Ruiz Asencio como en nuestro estudio coinciden: $401 \mathrm{H} / \mathrm{IO}$ IO-IId.C.

La secuencia de piezas según los distintos años de acuñación es casi ininterrumpida en toda la banda cronológica que abarca, faltando algunos años: $333 \mathrm{H} ; 335 \mathrm{H} ; 359 \mathrm{H} ; 363 \mathrm{H} ; 365 \mathrm{H}$; $366 \mathrm{H} ; 369 \mathrm{H} ; 37 \mathrm{I}-7 \mathrm{H} ; 380 \mathrm{H} ; 385 \mathrm{H}$.

La identificación de las monedas clasificadas por Ruiz Asencio con las estudiadas es prácticamente imposible. En el artículo las monedas aparecen clasificadas utilizando a Miles (MILES, 1960), sin que aparezca el peso o el módulo, por lo que establecer una correspondencia entre las piezas de los distintos estudios es muy difícil.

\section{ENCUADRE HISTÓRICO}

Así, pues, estas fechas dadas nos delimitan el encuadre histórico al que circunscribir este hallazgo, siendo, obviamente, el Califato.

El mantenimiento del Estado se debe a la fiscalidad y a la concentración de recursos en Córdoba. El sistema fiscal parece esencialmente una continuidad del emiral basado en la moneda, mientras que la influencia que se ejerce en la zona del Magreb va a permitir la llegada de oro, reiniciándose la acuñación de dinares. No obstante, la principal moneda seguirá siendo el dirhem de plata, de los que se ha estimado que debieron acuñarse varios millones de piezas al año.

'Abd al-Raḥmān III, que en el 317H/929d.C establece el Califato, será sucedido por su hijo al-Hakam (366H/976d.C), durante cuyo reinado continuó la estabilidad y prosperidad alcanzada en el período anterior. Tras su muerte, Hišām || será nombrado califa con tan sólo | | años. Los altos funcionarios se enfrentarán por el poder, siendo Muhammad Abī 'Amīr al-Mansūr bi-llah ("Almanzor" en las fuentes cristianas) el que consiguió ser nombrado hayib, ocupándose de administrar el poder, recluyendo a

3 Catálogo n 5, 6 y 7. 
Hišam en Madinat al-Zahra'. Estos hechos inician el período conocido como amirí. Será el segundo de sus hijos el que, tras su designación como heredero por parte del califa, consiga, a raíz de los acontecimientos expuestos, escandalizar a la población y activar la oposición de numerosos sectores, encabezados por la familia omeya y la aristocracia cordobesa. Tras su asesinato se inicia un período de inestabilidad y guerra civil conocido como fitna o crisis del Califato.

La historia de Ŷayyān en estos momentos se caracteriza por una enorme confusión, ya que en un corto espacio de tiempo se suceden intervenciones de beréberes y eslavos, en beneficio de los distintos pretendientes al gobierno del Califato.

Según Ibn Idāri ${ }^{4}$, en el año 40 IH/I0 IOd.C los beréberes de Zawi b. Ziri, que reconocían a Sulaymān al-Musta'în como califa, tras vencer a Muhammad al-Madhī en tierras de Ronda, realizaron alganzúas por tierras de Elvira, Jaén, Málaga y Algeciras. Algo después, cuando alMusta'în inició su segundo mandato como cali$\mathrm{fa}(403 \mathrm{H} / \mathrm{I} 0$ I 2d.C), repartió algunos territorios del centro y sur de al-Andalus entre los jefes de las tribus ${ }^{5}$ bereberes. Ŷayyān, en este reparto, correspondió a los Banū Birzāl y Banū Îfran.

El dominio de estas dos tribus zanata, si llegó a producirse, no se prolongó durante mucho tiempo ni arraigó lo suficiente como para significar la formación de un territorio controlado firmemente en estas tierras (AGUIRRE, JIMÉNEZ, 1979). Estas tribus abandonaron el territorio jiennense ya que se asentaron en tierras de Carmona los primeros y en Ronda los Banū İfran.

Está claro que entre los años $400 \mathrm{H}-412 \mathrm{H}$ / 1009-102 I d.C se vive un período de inestabilidad y de presiones constantes, que quedan enmarcadas dentro del cuadro de luchas por el poder que se vive en todo el territorio de al-Andalus y especialmente en Córdoba, su capital. La repercusión de los sucesos que tie-

4 lbn Idari, Al-Bayan.

5 QABA'IL, plural en árabe de la palabra QABILA, tribu. nen lugar durante los años de la fitna se van a manifestar en el territorio de Jaén a través de una serie de cambios de diverso tipo (demográficos, administrativos, políticos, militares,....) relacionados entre sí.

Esta crisis afectó de forma importante a la población. Durante mucho tiempo la inseguridad fue grande, porque los distintos grupos de "combatientes" se mantuvieron a base de saquear y robar a las poblaciones campesinas que encontraban en el curso de sus expediciones.

\section{ESTUDIO DE LAS PIEZAS}

El presente trabajo se divide en función del estudio pormenorizado de las piezas pertenecientes al gobierno de cada uno de los califas y un grupo independiente dedicado a las piezas fatimíes, tratando cada uno de los aspectos que forman parte del estudio numismático de dichas monedas (composición, cecas, metrología, tipología,...)

\begin{tabular}{|c|c|c|}
\hline CALIFA & AÑOS & $N^{\circ}$ Monedas \\
\hline 'Abd al-Raḥmān III & $\begin{array}{l}300-350 \mathrm{H} \\
9|2-96| \text { d.C. }\end{array}$ & 75(Catálogo: I-75) \\
\hline Al-Ḥakam & $\begin{array}{l}350-366 \mathrm{H} \\
961-967 \text { d.C. }\end{array}$ & 39(Catálogo: 76-114) \\
\hline \multirow[t]{2}{*}{$\begin{array}{l}\text { Hišām II } \\
\text { (2 reinados) }\end{array}$} & $\begin{array}{c}366-399 \mathrm{H} \\
976-1009 \text { d.C. }\end{array}$ & 74(Catálogo: | |5- | 88) \\
\hline & $\begin{array}{c}400-403 \mathrm{H} \\
1010-1013 \text { d.C. }\end{array}$ & I5(Catálogo: 189-203) \\
\hline Muḥammad II & $\begin{array}{c}399-400 \mathrm{H} \\
1009-1010 \mathrm{~d} . \mathrm{C}\end{array}$ & I0(Catálogo: 204-212) \\
\hline Sulaymān & $\begin{array}{c}400 \mathrm{H} \\
1009-1010 \text { d.C. }\end{array}$ & I2(Catálogo: 213-224) \\
\hline Fatimíes & $\begin{array}{c}365-41 \text { I } \\
975-1021 \\
\text { d.C. }\end{array}$ & 28(Catálogo: 228-256) \\
\hline Sin Fechar & & 3(Catálogo: 225-227) \\
\hline TOTAL PIEZAS: & & 256 \\
\hline
\end{tabular}

Tabla 2

La subida al poder de 'Abd al-Raḥmān III (300H/9 I2d.C) supone el comienzo de lo que acabará siendo el Califato de Córdoba con 
todo lo que esto conlleva: el que sus gobernantes tuvieran en sus manos unas prerrogativas que estimaban como propias desde el derrocamiento de su dinastía en Oriente por los abbasíes, siendo la acuñación de moneda uno de los ejemplos más notables de este hecho. Los fatimíes ya habían llevado a cabo una acción similar en el Norte de África, con lo que están conviviendo tres califas en el horizonte del mundo islámico.

Durante los primeros años se dedicará a extender su poder, sofocando definitivamente las sublevaciones muladíes, una situación de inestabilidad y de falta de recursos que se refleja en la ausencia de emisiones monetarias. Consolidada la paz y su autoridad, comienza de forma ininterrumpida la acuñación de moneda, 316H/928d.C, año en el que las fuentes citan la apertura de la ceca en Córdoba, con el nombre de al-Andalus.

En sustitución de la Sura 12 del Corán que aparecía en los dirhemes del emirato, se va a colocar el nombre del soberano con sus títulos y laqab (títulos honoríficos) en la leyenda central del reverso. La fórmula utilizada será "EI imán victorioso por la fe de Dios, 'Abd al-Raḥmān emir de los creyentes" (Lám. I).

La leyenda central de anverso sigue con la misma distribución que en el emirato (TAWHID o Profesión de fe musulmana), pero aparece una innovación: la inclusión de nombres que corresponden a los ashāb al-sikka (o prefectos de ceca). Este dato es de inestimable interés, ya que nos permite, al menos, poder encuadrar cronológicamente piezas en las que fecha, que se localiza en la orla, aparezca dañada. Además de poder establecer toda la secuencia de monedas califales e, incluso, ofrece la posibilidad de clasificar determinados grupos en función de dichos nombres (Lám. 2).

Este nuevo modelo va a ser continuado por los sucesores del primero de los califas andalusíes con escasas variaciones, salvando el cam- bio de los nombres y otros datos, dependiendo de quién esté en el cargo. Se puede concluir, por tanto, que las piezas de 'Abd al-Rahmān III presentan un cambio, en lo que a diseño tipológico se refiere, en comparación con el emirato, articulándose en función de la distribución de la leyenda y de la presencia de los nombres de los funcionarios (ashāb al-sikka).

Los cambios o alteraciones de estos modelos, no ya sólo en lo que se refiere a tipología sino también al peso y módulo de las piezas (como sucede en la serie Hišãm de los años 334-5H/945-6d.C, por ejemplo ${ }^{6}$ ) puede obedecer no sólo a criterios estilísticos sino que puede servir para diferenciar las distintas emisiones entre sí, pero quizás la comprensión de este fenómeno se nos escape por la falta de datos con los que contrastar estas hipótesis.

En el año 336H/947d.C se traslada la ceca a la ciudad palatina de Madīnat al-Zahrā', siendo la única ceca en funcionamiento en los siguientes 29 años, es decir, abarcando el resto del reinado de 'Abd al-Raḥmān III y al-Hakam.

Con al-Hakam y con Hišām la moneda no va a sufrir grandes cambios, aunque empieza a aparecer el nombre del haȳīb ("Primer Ministro") (Lám. 3).

También en el reinado de al-Hakam aparecerá un nombre cuya influencia y poder va a ir creciendo; nos referimos a Muhammad lbn Abī 'Amir (Almanzor). La información que a través de la Numismática se infiere de su ascenso al poder es muy ilustrativa: cuando al-Mansūr fue ascendido, el cargo de encargado de ceca fue dado a Ahmad b. Muḥammad b. Hudayr, que acuñará moneda entre los años $360 \mathrm{H} / 970 d . C$ y $363 \mathrm{H} / 973 d . C$. Es interesante observar cómo el nombre de 'Amir va a seguir apareciendo en las monedas durante estos años, aunque él no sea el prefecto de ceca, colocado bajo el del califa reinante (en el reverso). Sin embargo, aunque el nombre de Muhammad ${ }^{7}$, el prefecto de ceca, aparece todavía

\footnotetext{
6 Catálogo n० 16 y 17.

7 Catálogo n 102 y 106.
} 
durante algunos años, pronto desaparece y el de su sucesor no llega a aparecer ni una sola vez, mientras que sí se mantiene el de Abi 'Amir, aunque esto ocurre ya bajo el reinado de Hišām II. Durante el período de gobierno de este califa omeya, el que gobierne realmente al-Andalus será al-Mansūr, que maneja al califa a su voluntad (Lám. 4).

Desde el año 372H/982d.C al 376H/986d.C se interrumpe la acuñación de moneda en alAndalus siendo la primera ruptura en una cadena ininterrumpida de 55 años, durante todo el Califato. Este período es de gran actividad militar en las zonas de frontera, pero el Estado, para evitar el colapso, debe proporcionar numerario con el que poder pagar y recibir impuestos, aunque ampliando las remesas civiles y elevando los impuestos se podría afrontar el pago del ejército sin recurrir en exceso al tesoro estatal (PELLICER Y BRU, 1986). Sabemos, por situaciones similares en al-Andalus, que los períodos de fuerte convulsión social y política suelen reflejarse, y de forma negativa, en la emisión de moneda, como ocurrió en los últimos años del emirato independiente o en los primeros años del gobierno de 'Abd al-Raḥmān III.

La vuelta a la acuñación debe relacionarse con los sucesos políticos de período en que Abī 'Amîr comenzó su andadura hacia un mayor control del aparato del Estado, empezando a usar en el año 37|H/98|d.C su laqab de alMansūr bi-llāh.

En los últimos años del gobierno de alHakam II (359-365H/969-975d.C) el peso medio de las monedas se había elevado considerablemente, $y$, sin duda, el nombramiento de Abì 'Amir como prefecto de ceca está directamente relacionado con la aparición de un nuevo sistema metrológico, marcado por la elevación del peso de las piezas. Consideramos, por tanto, que hablar de una reforma monetaria de Hišām II no sería del todo correcto, siendo más exacto hablar de la reforma de Ibn Abī 'Amîr, verdadero artífice de la misma, ya que debemos tener en cuenta que el tercero de los califas omeyas heredó un sistema que ya se había experimentado en época de su padre (MARTíNEZ SALVADOR, 1992).

La ceca cambiará y vuelve a verse en las monedas el nombre de al-Andalus $(365 \mathrm{H} /$ 975d.C), localizada nuevamente en la ciudad de Córdoba. Este cambio puede responder al aumento de poder de al-Mansūr y al cambio de residencia del califa.

A estas acuñaciones hay que añadir las realizadas en el Norte de África, muestra del control que sobre esta zona se ejerce sobre todo a raíz de la agresiva política llevada a cabo por Almanzor. Son las acuñaciones de Madīnat Fās. Será esta ciudad, junto con Siŷilmāsa (Segilmesa), escenario de la pugna fatimí-omeya en el Magreb. No hay duda sobre el control omeya de la ciudad en el comienzo del reinado de Hišām II (366H/976d.C), aunque dicho dominio debió durar poco ya que existe un dirhem fatimí acuñado en Fās en el año 379H/989d.C, confirmándose de esta forma el éxito de la expedición realizada contra la ciudad por un vasallo fatimí.

Acerca de estas acuñaciones debemos referirnos a su mala calidad; a veces por falta de espacio sólo aparece la unidad de la fecha (Lám. 5).

El primero de los califas pertenecientes a este momento de guerra civil o Fitna ${ }^{8}$ será Muhammad al-Mahdī, también miembro de la familia omeya. Aparecen en este hallazgo piezas de los dos años en que reinó, presentando las mismas características que se han venido documentando durante todo el califato, lo que supone una continuidad de las emisiones de Hišãm, ya que la ceca peninsular es la misma (Lám. 6).

En el reinado de Sulaymān se documenta una novedad que viene representada por la aparición del nombre del Príncipe heredero en la I á ó $5^{a}$ línea del reverso (waliy al-'ahd/ Muhammad) (Lám. 7).

8 FITNA es el nombre con el que se denomina en las crónicas a este período de "guerra civil" entre los distintos partidos o grupos de poder de la sociedad de al-Andalus (andalusíes, beréberes y eslavos). 
En el año 400H/IO IOd.C, vuelve a subir de nuevo al trono Hišām II, siendo las monedas emitidas por él las más escasas en número (de los tres califas que emiten en la fitna), manteniéndose dentro de la tónica general del Califato.

Después de esto el califato va a desaparecer, el poder de los califas se desvanece, aunque nominalmente su existencia se va a extender hasta el año 422H/I030d.C, apareciendo a continuación una multitud de pequeños estados, los llamados reinos de taifas, cuya diversidad política se verá reflejada en el testimonio numismático con la aparición de cecas diversas, nombres propios y títulos de gobernantes que contrastan con el centralismo en la producción que se dio durante todo el período califal.

En lo que se refiere a las piezas fatimíes, conviene abordarlas aparte. Este Estado emitía moneda de plata y de oro, así como sus respectivas fracciones, siendo especialmente comunes las de $1 / 2$ y I/3 de dirham (BROWN, 1984), que eran las que más circulaban en la Península (MARTíNEZ SALVADOR, 97-98).

El que aparezca moneda norteafricana, y concretamente fatimí, en los hallazgos peninsulares del siglo $V$ de la Hégira es algo bastante común que ha llamado, desde hace tiempo, la atención de los investigadores. En nuestro caso aparecen un total de 28 monedas, de las cuales una ${ }^{9}$ se adscribe al período 365-86H/97599d.C bajo el gobierno de al-'Aziz y el resto 10 a los años 386-4I|H/996-I020d.C, con alHākim. El dar una cronología tan amplia a la que asociar estas piezas responde a que, debido a su mal estado, nos ha sido imposible leer su fecha, adscribiéndolas a la cronología del califa al que pertenecen.

Obviamente, puesto que el año de cierre es el $40 \mathrm{lH} / \mathrm{IO} \mathrm{IOd}$. C, se entiende que estas monedas llegaron a la Península antes de esta fecha.

Debemos apuntar el hecho de que serán los fatimíes los primeros en separarse de los tipos totalmente epigráficos impuestos en la reforma de 'Abd al-Malik (699d.C) los que introduzcan una nueva tipología acorde con sus preceptos shiíes (al-Mu'iz, 3|4H/952d.C). Se trata de un diseño de círculos concéntricos que manifiesta su repulsa hacia los principios sunníes tanto en lo político como en lo religioso. Aunque su mensaje pronto se va a suavizar, las monedas fatimíes quedarán marcadas por un estilo que las hará totalmente diferentes de las de sus vecinos, que todavía seguían siendo sunníes (BATES, 1982) (Lám. 8).

La ceca de acuñación no ha sido posible leerla o, en todo caso, corroborarla, ya que Ruiz Asencio (RUIZ ASENCIO, 1967) da como lugar de acuñación al-Mansūriya (Figura I).

El aspecto más interesante de estas piezas viene a partir del estudio de su histograma de pesos, en el que se observa la existencia de tres grupos (Figura 2):

a) Pesos entre I'57 y Igr, que debemos identificar con fracciones de 1/2 de dirhem (BROWN, 1984).

b) Pesos entre 0'90 y 0'40gr. con equivalencia a I/4 de dirhem (BALOG, 1972).

c) Entre Igr. y 0'80gr. -"Criterio visual"-. En función del recorte de todas sus orlas o exclusivamente de la orla más externa, ya que si nos fijamos en sus pesos exclusivamente, vemos que no pueden ser adscritas a uno u otro grupo de forma clara.

- I/2 dirhem, cortes que siguen la primera línea concéntrica.

- I/4 dirhem, no hay orlas, sólo aparece el núcleo central.

Si observamos otros hallazgos peninsulares en los que también aparece moneda fatimí ${ }^{\prime \prime}$ (MARTÍNEZ SALVADOR, 97-98) vemos que siempre aparecen como divisores de moneda $y$, en muy contadas ocasiones, como moneda unidad.

\footnotetext{
9 Catálogo nº 229.

10 Catálogo n² 230 a 256.

I I Baena (córdoba), Trujillo (Cáceres) o Sierra de Cazorla (Jaén).
} 
Los pesos de estas piezas, en lo referente a la plata, son ligeramente inferiores a los documentados en el califato fatimí. El sistema trimetálico fatimí, que se basaba especialmente en el oro, utilizaba la plata en pequeñas cantidades y casi siempre como fracción, quizás por esto sean las piezas de divisores de dirhem las únicas que aparecen en los hallazgos.

Pero la presencia de estas piezas en ocultamientos peninsulares debe evidenciar algo. En primer lugar, el uso por parte de la población de unas piezas no acuñadas por el Estado cordobés, pero que, al menos en la esfera del comercio local, debía ser aceptada. Y, por otro lado, la comparación de las fechas de los hallazgos con las de las piezas fatimíes en ellos incluidas, muestra una correspondencia entre las mismas (en nuestro caso $322-40 \mathrm{IH}$ frente a $365-4 \mid \mathrm{IH}$ ), siendo un indicador de que las relaciones entre ambos mundos eran constantes y en continua renovación.

Conviene destacar a este respecto que a partir del año 360H/970-I d.C, las cecas orientales norteafricanas acuñan moneda fatimí y ésta no llega a al-Andalus, llegando, sin embargo, piezas de cecas occidentales. Cuando las cecas occidentales dejan de acuñar moneda, las piezas fatimíes desaparecen de los hallazgos peninsulares. Esto, sin duda, está en conexión con el tipo de relación económica que se mantiene entre las comunidades de ambos lados del estrecho.

El aspecto de la metrología califal ha sido tratada en mayor medida y, quizás, más a fondo que la del emirato. Pellicer i Bru en su trabajo sobre la metrología de las acuñaciones del califato de Córdoba (PELLICER i BRU, 1988), calculó el peso medio de los dirhemes para cada uno de los tres califas cordobeses.

Posteriormente Canto, Cardito y Martínez completan los datos ofrecidos por Pellicer, al calcular el peso medio de dirham teniendo en cuenta quien ocupaba el cargo de ashāb al-sikka - los diferentes períodos de gobierno de cada califa (CANTO, CARDITO, MARTíNEZ, 1994-5).
Según los estudios realizados a partir de la fecha de 330H/94 I d.C, el volumen de emisión aumenta de forma notable, con los índices más altos en determinados años, como, por ejemplo, el momento de traslado a Madinat alZahrā', siendo los años 336-9H/947-50d.C los que suponen un esfuerzo notable en la producción de moneda (CANTO, CARDITO, MARTÍNEZ, 1989).

Esto se vuelve a repetir en las piezas que componen este hallazgo, observándose un mayor número de piezas dentro de los años $337 \mathrm{H} / 948 d$.C y $338 \mathrm{H} / 949 d$.C, con una notable disminución en los años 339H/950d.C y $340 \mathrm{H} / 95$ I d.C, para presentar el pico más alto en el 34I-2H/952-4d.C. (Figura 3).

\section{ALTERACIÓN Y CONSERVACIÓN DE LAS PIEZAS}

Aparte de lo ya comentado con respecto a las alteraciones de las piezas fatimíes, como sucede en un gran número de los hallazgos y sucedió en el emirato, también vuelve a darse el fenómeno de la partición de moneda. Debe tratarse de una manipulación local por parte de la población que se abastece, así, de una moneda fraccionaria que el Estado no provee (CANTO, 199I) (Lám. 9)(Figura 4).

Para nuestro estudio hemos abordado el problema con la siguiente clasificación:

- Enteras: 66\%.

- Recortadas: 13\%. Afecta ligeramente a la pieza $(<25 \%)$.

- Muy recortadas: $9 \%$. Afecta a la pieza entre un 25 y un $50 \%$.

- Partidas: 3\%. Se conserva $\leq 50 \%$ de la pieza.

- Fragmentos: 3 \%. Entre un 1/3 ó 1/4 de la pieza.

- Borradas: 6\%. Presentan una mala conservación en su grafía.

Otra alteración a tener en cuenta es la de las perforaciones, pudiendo aparecer una o dos. 
Las monedas perforadas localizadas en este hallazgo ${ }^{12}$ se encuentran entre las piezas de los califas 'Abd al-Raḥmān III a Hišāan II ( I er reinado). Una hipótesis para explicar la presencia de dichas perforaciones es la de suponerles un uso en transacciones en el ámbito privado (CANTO, 1986ª ) el ser un método de transporte de las piezas (Lám. 10).

Llama la atención el gran número de monedas definidas como "borradas" (otro tipo de alteración), es decir, que su epigrafía no se encuentra en un estado óptimo para su lectura, debido especialmente al uso (Figura 5).

Es interesante la apreciación de que las piezas pertenecientes a los tres últimos califas (años 399H a $40 \mathrm{lH}$ : Muḥammad, Sulaymān y Hišām II, $2^{\circ}$ reinado) no presenten tipo alguno de alteración o manipulación física; esto es indicativo del corto espacio de tiempo que estuvieron en circulación, ya que entre su acuñación y el cierre del hallazgo trascurrieron apenas un par de años.

\section{COMPARACIÓN CON OTROS HALLAZGOS. CONCLUSIONES}

Este hallazgo fue, obviamente, ocultado en un momento y lugar precisos, por lo que no debe ser estudiado aisladamente. Se documentan hallazgos similares tanto en composición como en fecha de cierre ${ }^{13}$ :

\section{"TESORO HISPANO-ÁRABE HALLADO EN TRUJILLO (CÁCERES)".}

(NAVASCUES, 1957)

(320H/932d.C a 407H/I0I6d.C)

2 fragmentos de dirhem emiral.

Piezas y fragmentos de dirhemes de todos los califas. También piezas fatimíes.

Este hallazgo, junto con el de Marroquíes Bajos (Jaén) (CANTO, GARCíA, RUIZ, 1997), puede ser quizás de los pocos conjuntos que penetran un poco más en este período de inestabilidad que abarca la primera decena del siglo VH/XId.C, sin que el ocultamiento se produzca justo en el inicio de las hostilidades.

\section{“UN TRESOR DE DIRHEMS ARAB A SC-J".} (PELLICER Y BRU, 1982).

Tesorillo encontrado en la Sierra de Cazorla, Jaén. Con una cronología que abarca desde el 318/930d.C a 40IH/I0IOd.C.

Piezas de todos los califas hasta el segundo reinado de Hišām II.

8 piezas fatimíes.

\section{"TESORILLO DE MONEDA CALIFAL Y FATIMÍ EN CÓRDOBA (III)"}

(ALFARO ASINS, 1990)

(322H/933d.C a 402H/IOI Id.C)

382 dirhemes califales. 31 piezas fatimíes.

También consideramos apropiado hacer referencia a los hallazgos que geográficamente han sido encontrados cercanos a éste que aquí tratamos, y que posean una fecha de cierre similar. El circunscribir los hallazgos que citamos a la zona geográfica cercana a Jaén sólo obedece al hecho de no querer hacer una lista interminable. Además, estimamos que es en una escala espacial pequeña en la que podemos llegar a dibujar un panorama más concreto de la realidad histórica de este momento.

\section{"HALLAZGO DE MONEDAS EN MARRO- QUÍES BAJOS, JAÉN."}

(CANTO, GARCÍA RUIZ, RUIZ QUINTANAR, 1997). (330H/94Id.C a 405H/I0I4d.C)

Compuesto por 201 monedas de plata, dirhemes, y un lote de fragmentos. La abundancia de piezas acuñadas en el año $405 \mathrm{H} /$ IOI 4 d.C (fecha de cierre) y su buen estado de conservación inducen a pensar que el ocultamiento debió realizarse en un período muy cercano a esta fecha.

1227 monedas con dos perforaciones y 5 con una perforación.

13 Es decir, centran su cronología en el califato, poseen piezas de los distintos califas y una representación de las dinastías norteafricanas. 
"HALLAZGO DE ERMITA NUEVA, ALCALÁ LA REAL (JAÉN)."

(CANTO, IBRAHIM, 1997).

(326H/937d.C a $40 \mathrm{IH} / \mathrm{I} 0 \mathrm{IOd} . \mathrm{C})$

Piezas califales (todos los califas) y fatimíes. Aparecen también joyas.

\section{"TESORO DE ELECTROMAGNÉTICAS I, CÓRDOBA."}

(MARCOS POUS, VICENT ZARAGOZA, 1990)

Con una cronología que abarca desde el $330 \mathrm{H} /$

94 Id.C al $405 \mathrm{H} / 1014 d . C$.

\section{"TESORO URBANIZACIÓN DE LA SAGRA- DA FAMILIA DE CAÑERO, CÓRDOBA"}

(MARCOS POUS, VICENT ZARAGOZA, 1990)

Las piezas más antiguas corresponden al reinado de 'Abd al-Rahman III, siendo la fecha de cierre el $402 \mathrm{H} / 10 \mathrm{II}-2 \mathrm{~d}$.C.

\section{"TESORO DE ELECTRO MAGNÉTICAS II. CÓRDOBA"}

(MARCOS POUS, VICENT ZARAGOZA, 1990)

Con piezas acuñadas por todos los califas, terminando con el segundo reinado de Hišām II. El hallazgo se cierra en el año 406H/I05 Id.C.

Estos ocultamientos, claramente relacionados, en función de sus fechas de cierre y por localización, con el período de la fitna, son exponentes de la tendencia de la población a esconder estos bienes con la intención de volver a por ellos, siendo el hallazgo motivo de este estudio otro ejemplo más de lo defendido hasta aquí. Estos conjuntos citados serían una evidencia arqueológica que estaría constatando la situación política atestiguada por las fuentes escritas.

Por otro lado, el hecho de que la composición de los hallazgos analizados sea casi exacta evidencia otro punto de gran interés, que nos permitirá una valoración de los tipos de piezas que circulaban y que eran usados por la población: primero, el que aparezcan monedas de los distintos califas indica que aunque estuvieran bajo el reinado de otro mandatario, las piezas de los anteriores seguían estando en uso, es decir, que eran aceptadas por la población y por el Estado. Segundo, la presencia de piezas norteafricanas indica una utilización activa de las mismas, es decir, su aceptación dentro del sistema califal, al equipararlas en el peso de las piezas o fracciones de las mismas que emitía el poder cordobés.

Esto nos puede llevar a pensar que, si se equiparan las piezas en función del peso, irealmente su circulación se realizaba a la talla? Se paga algo con el valor nominal de una o dos monedas o por el peso estipulado que deben tener unas piezas controladas por el Estado. Si es indiferente el uso de piezas fatimíes o cordobesas, (al menos su uso está permitido, como demuestra que se encuentren en los hallazgos junto a las piezas andalusíes), con una tipología distinta pero con un peso estipulado de forma que se igualaran las diferentes leyes de las monedas, indica que su empleo se realizaba en función de su peso, lo cual no excluye que pudieran circular también en función de un valor teórico asignado a cada pieza o fragmento de pieza.

Así pues, el fenómeno de los ocultamien$\operatorname{tos}^{14}$ es, de hecho, una de las fuentes que más información proporciona para la investigación numismática, ya que, además del valor propio de cada moneda, del conjunto del hallazgo se puede extraer un conocimiento que sobrepase la simple enumeración o clasificación positivista de las piezas, entendiéndolas como objetos fiscales o económicos así como su imbricación en las poleas de una sociedad a la que sirve y de la que es fruto.

Resumiendo, consideramos que el estudio de estas 256 monedas andalusíes es un ejemplo atractivo y representativo a través del cual acercarnos un poco más al mundo y la sociedad que las usó......y ocultó.

14 Proceso por el cual alguien ha escondido u ocultado, con la idea de recobrarlas después, las monedas (CANTO, IBRAHIM, 1997). 


\section{BIBLIOGRAFÍA}

AGUIRRE SÁDABA, J. JIMÉNEZ MATA, Ma C. (1979) Introducción al Jaén islámico (Estudio geográfico-histórico). Instituto de Estudios Giennenses. Excelentísima Diputación Provincial. Jaén.

BALOG, P. (1972) "A hoard of I// 6-th dirham fractions of the Fatimids caliph al-Hakim bi-amr illah (386-4I I $\mathrm{AH}=996-1020$ AD) in the Vatican coin collection". Rivista Italiana di Numismática e Scienze Affini. Vol. LXXIV.

-(1976). "Sicilian type radiate dirhem of al-Mustasir billah struck in Aleppo". Numismatica e Antichità Classiche, V.

BARCELÓ, M. (1997). El Sol que salió por Occidente. Estudios sobre el estado omeya de al-Andalus. Universidad de Jaén.

BATES, M.L. (1982). Islamic coins. American Numismatic Society, Handbook 2. Nueva York.

BROWN, H.M. (1984) "Early silver coinage of the Fatimids". Rivista Italiana di Numismática e Scienze Affini. Vol. $L X X X V \mid$.

CANTO GARCÍA, A. (1986a). "Perforations in coins of the Andalusian Umayyad Caliphate: a form of demonetizacion?" Problems of Medieval Coinage in the Iberian Area 2, Avilés.

-(1986b). "La reforma monetaria de Qasim", Al-Qantara, 7.

- (1986c) "Los Ashāb al-Sikka de 'Abd al-Raḥmān III, según ibn Hayyān y el testimonio de las Monedas". Cuadernos de Prehistoria y Arqueología, 13-14.

-(1991) Cuestiones económicas y numismática andalusí. Aragón en la Edad Media, IX. Universidad de Zaragoza. 1991

-(1995) La moneda andalusí. En El Zoco. Vida Económica y Artes Tradicionales en al-Andalus y Marruecos. El Legado Andalusí, Madrid, pp.35-42, Fichas 1 17-187.

-(1999) "La Moneda Andalusí: ¿un modelo de moneda distinto?" Gaceta Numismática, 133.

-(1989) ;CARDITO,L; MARTíNEZ, C. "La metrología del Califato de Córdoba: las emisiones de plata de las cecas de al-Andalus y Madinat al-Zahrā' en el período 321399H/933-I008(9)". Gaceta Numismática, 94-95.

-(1997) ; GARCÍA RUIZ, G; RUIZ QUINTANAR, L. "El hallazgo de monedas califales de Marroquíes Bajos (Jaén)". Arqueología y Territorio Medieval, 4. Universidad de Jaén.

CODERA Y ZAIDÍN, F. (I878) "Títulos honoríficos y nombres propios en las monedas arabigo-españolas". Rev. Universidad de Madrid.

DOMÉNECH BELDA, C.(1993) "Revisión de un hallazgo de monedas árabes de Elche (Alicante)". III Jarique de Numismática Hispano-Árabe, Madrid.

FROCHOSO SÁNCHEZ, R. (1996) Las monedas califales. De ceca al-Andalus y Madinat al-Zahra' 3/6-403H,
928-1013 d-C. Publicaciones de la Consejería de cultura de la Junta de Andalucía y Obra Social y Cultural de Cajasur, Córdoba.

MARCOS POUS, A; VICENT ZARAGOZA, A.M. (1993)

"Los tesorillos de moneda hispano-árabe del Museo Arqueo-lógico de Córdoba", III Jarique de Numismática Hispano- Árabe, Madrid.

MARTÍNEZ SALVADOR, C. (1990) "Moneda fatimí en hallazgos peninsulares". Gaceta Numismática, 97-98.

-(1992) "Los ashāb al-sikka en las acuñaciones de Hišām II". Cuadernos de Prehistoria y Arqueología de la Universidad Autónoma de Madrid, 19.

MEDINA GÓMEZ, A. (1992) Monedas hispano-musulmanas. Manual de lectura y clasificación. Instituto Provincial de Investigaciones y Estudios Toledanos, Ser.3: Estudios, Catálogos y Repertorios, 16, Madrid.

MILES, G.A. (195I) Fatimids coins in the collections of the University Museum, Philadelphia, and the American Numismatic Society. The American Numismatic Society. Nueva York.

-(1960) The coinage of the Umayyads of Spain, Nueva York, The American Numismatic Society (2 vols).

NAVASCUÉS, J.M. ( 1957) "Tesorillo hispano-árabe hallado en Trujillo (Cáceres)". Numerario Hispánico, 6.I I.

-(1958) "Tesorillo de monedas de plata del Califato Cordobés y Fatimíes". Numerario Hispánico 7.14.

OCAÑA, M. (198I) Nuevas tablas de conversión de datas islámicas a cristianas y viceversa. Instituto Hispano-árabe de Cultura. Madrid.

PELLICER Y BRU, J. (1982) "Un tresor de dirhems árabas A SC-J". Acta Numismática vol.2.

-(1988) Al-Andalus. Las fuentes y la Numismática (Síntesis cronológico-metrológica de las acuñaciones del califato de Córdoba). Barcelona.

RUIZ ASENSIO, J.M. (1962) "Tesorillo de dirhems del Califato hallados en Jaén". Boletín del Instituto de Estudios Giennenses.

RUIZ QUINTANAR, L. (1997) Fragmentación de moneda en época omeya: el hallazgo califal de Haza del Carmen. Memoria de Licenciatura. Inédita. UAM.

SAÉNZ DIÉZ, J.I.(1984) Las acuñaciones del califato de Córdoba en el Norte de África. Madrid.

-(1986) Circulation and coinage by Hišām II in North Africa (366-399). Problems of Medieval Coinage in the lberian Area, vol.2.

VALENCIA, R; OLIVA,D; GÁLVEZ, M E. (1982) "Una propuesta para sistematización de la trascripción de textos y nombres árabes en trabajos de numismática andalusî". Acta Numismática, n 12.

VIVES Y ESCUDERO, A. (1893) Monedas de las dinastías arábigo-españolas. Madrid. (Reed. J. Cayón, Madrid 1978). 


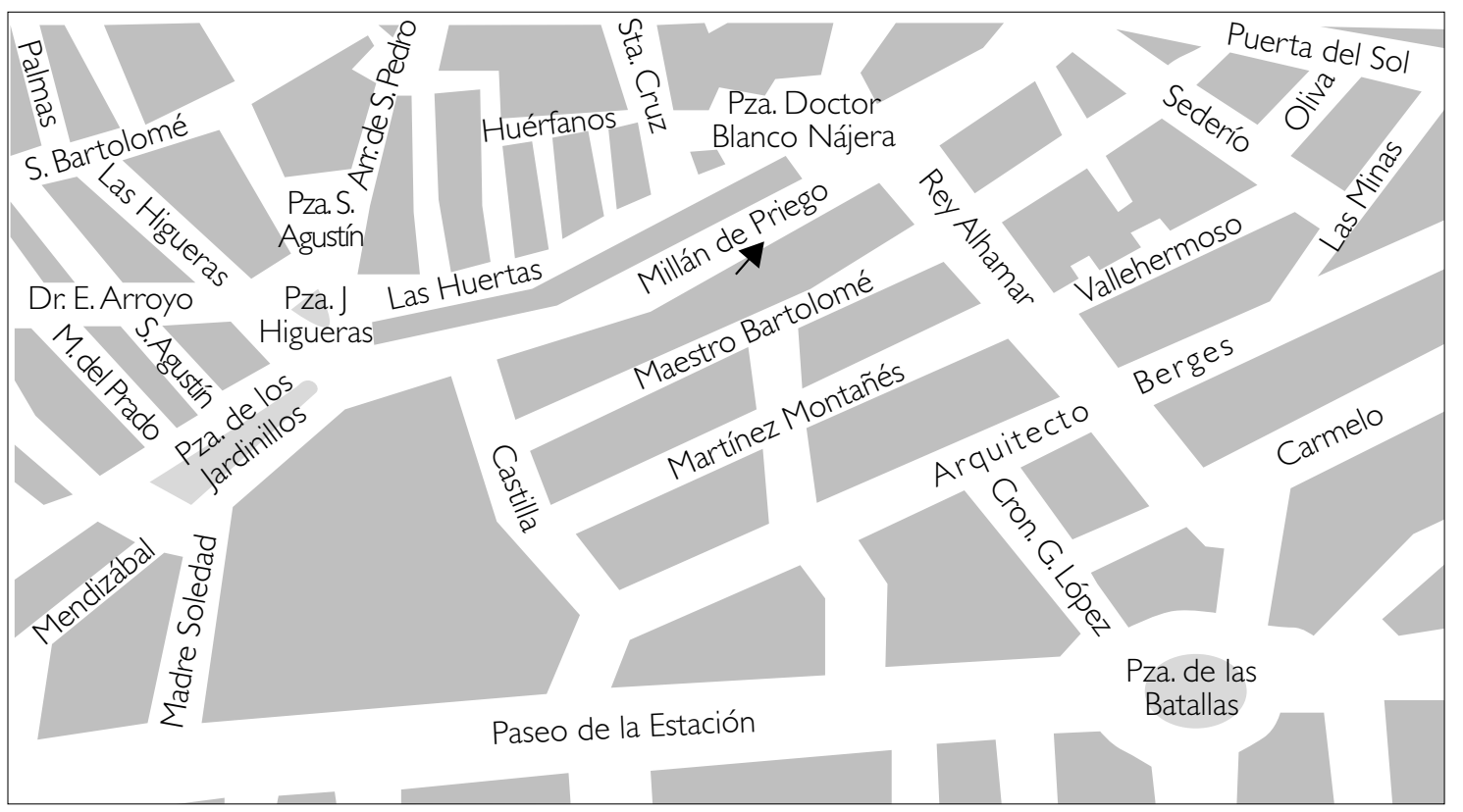

Fig. I. Localización del hallazgo en el mapa de la ciudad de Jaén.

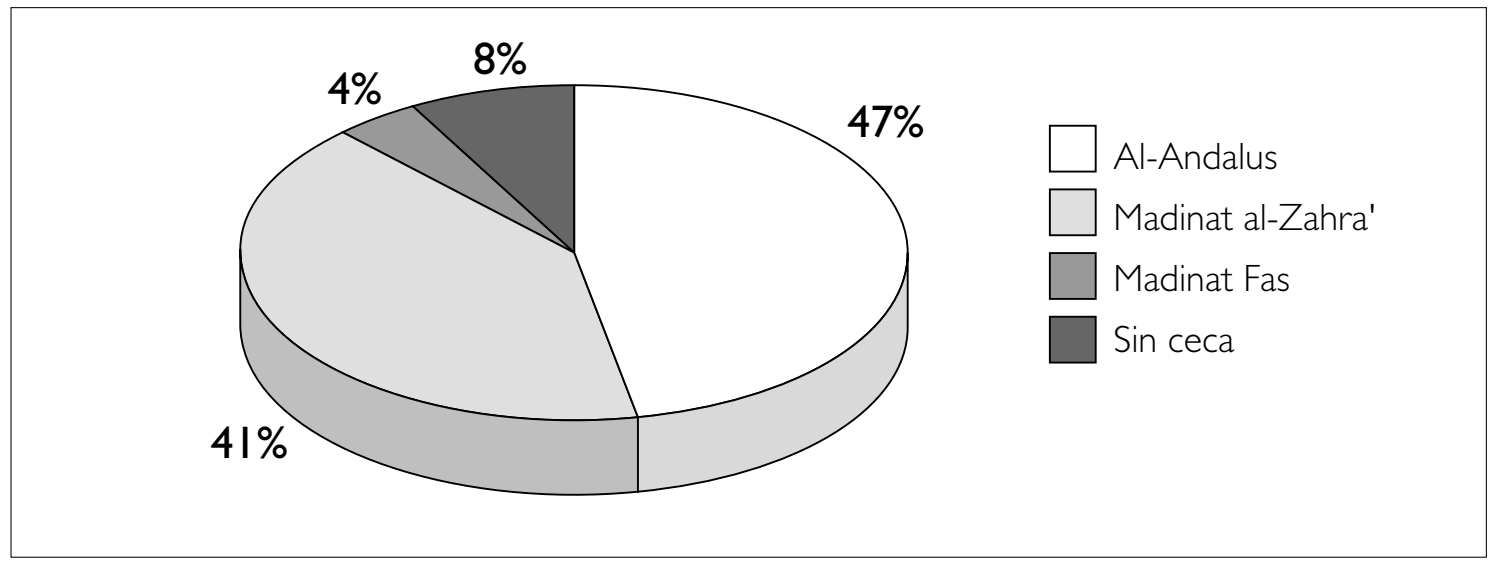

Fig. 2. Monedas por ceca de acuñación.

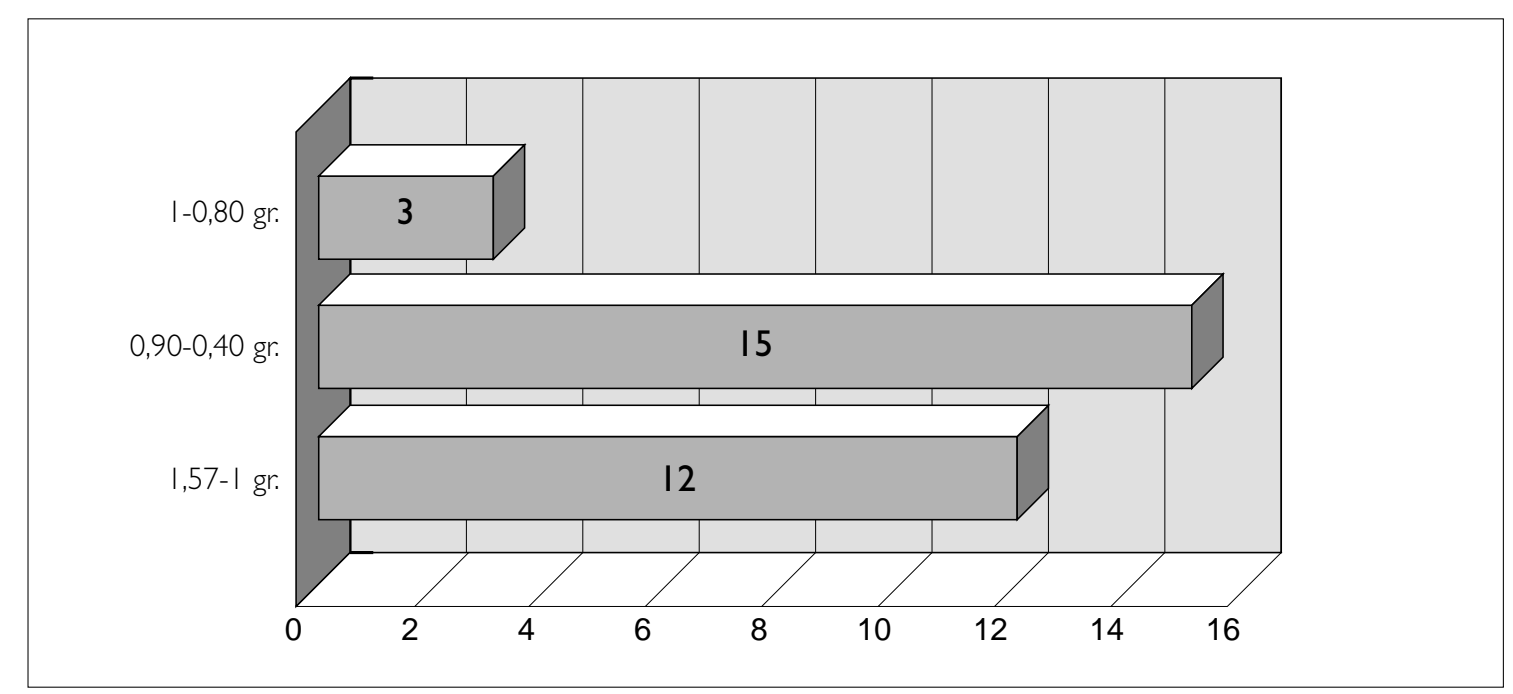

Fig. 3. Histograma de pesos de las piezas fatimíes. 


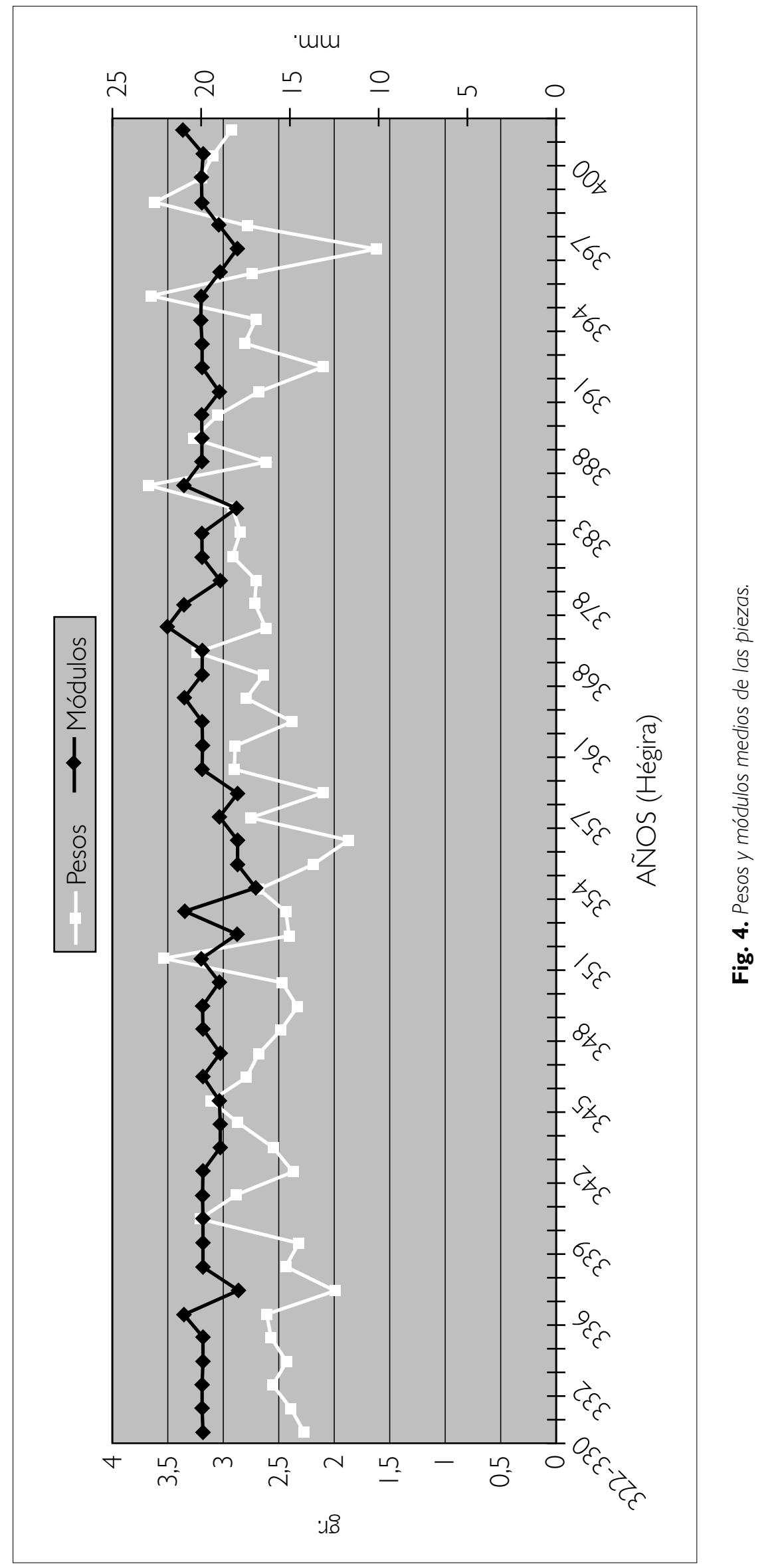




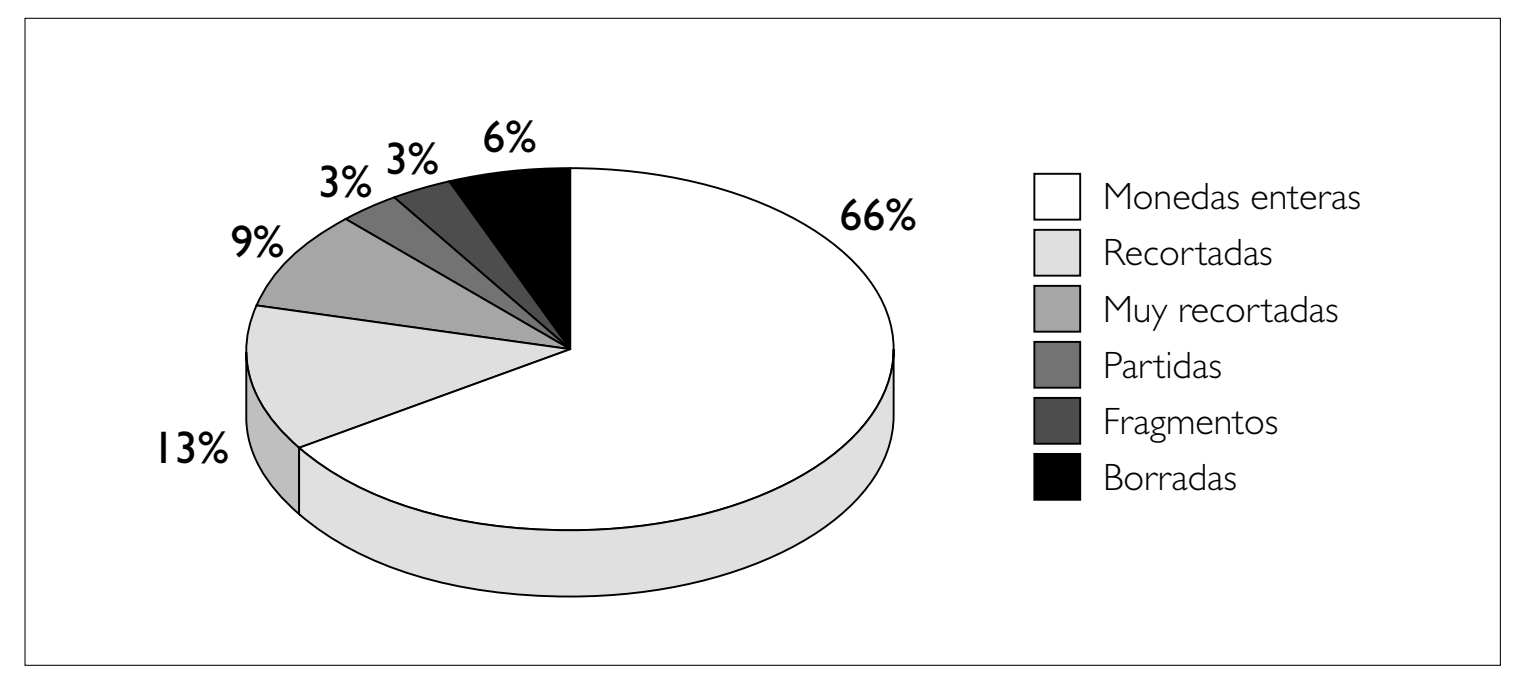

Fig. 5. Estado de conservación.

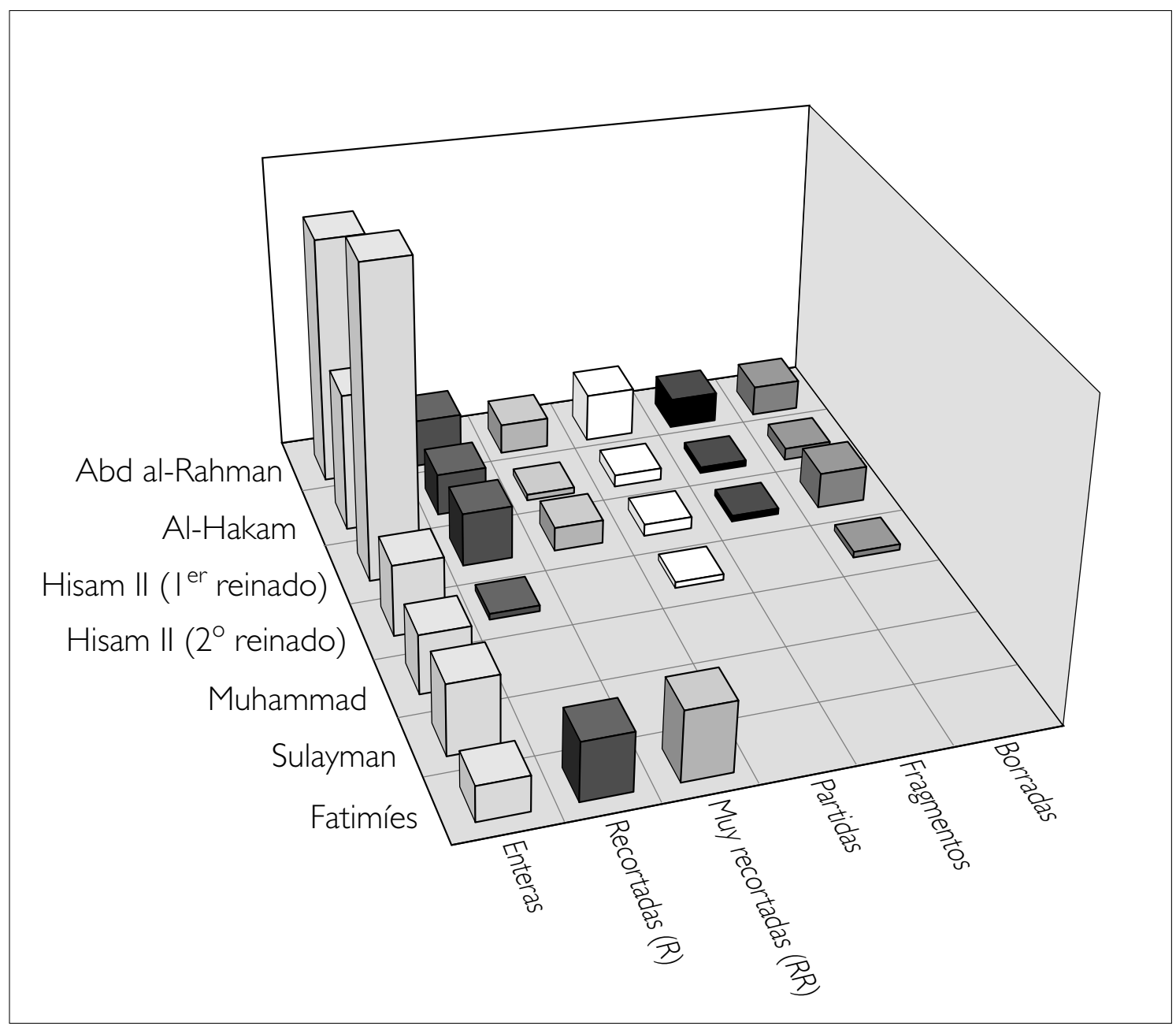

Fig. 6. Estado de las monedas. 


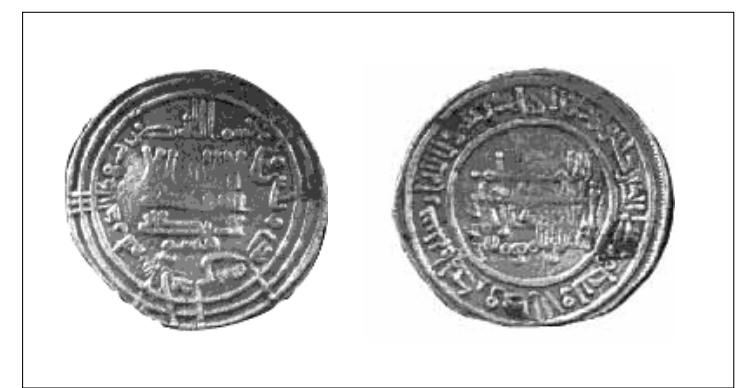

Lám. I. Catálogo n9 [V.397/M.229]

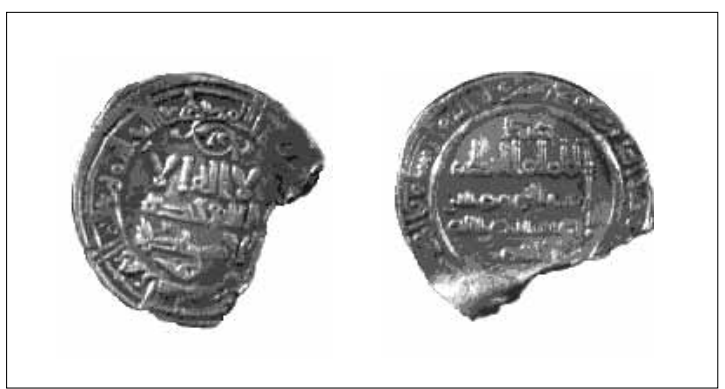

Lám. 3. Catálogo nº6 [V.449/M.243.r]

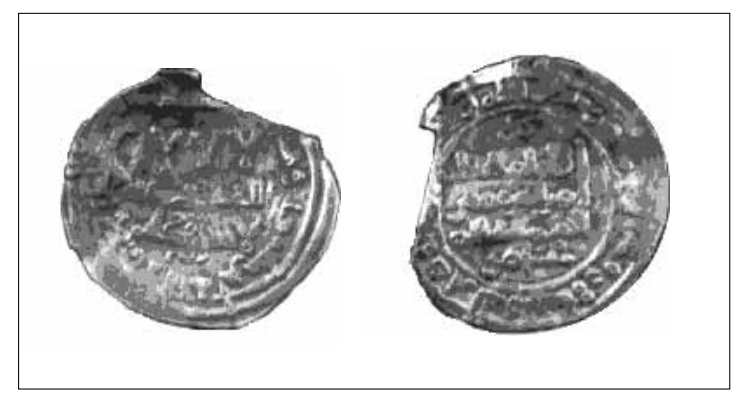

Lám. 5. Catálogo n’/ 35 [V.52 / /M.309.b]

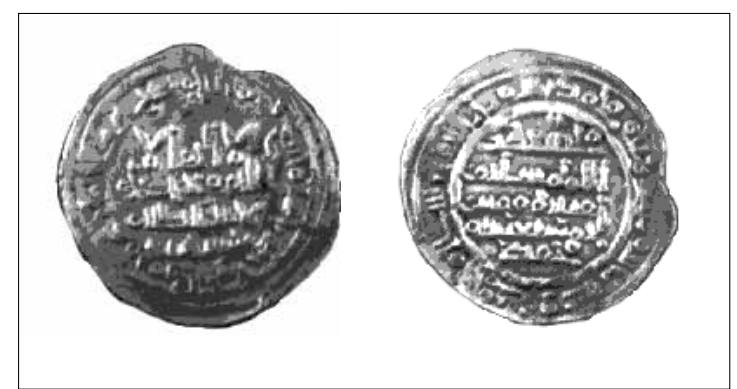

Lám. 7. Catálogo n²21 [V.696/M.343.e]

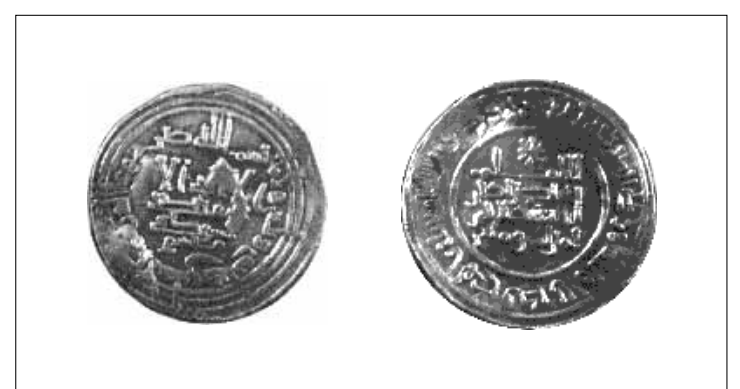

Lám. 2. Catálogo no II [V.397/M.219.c]

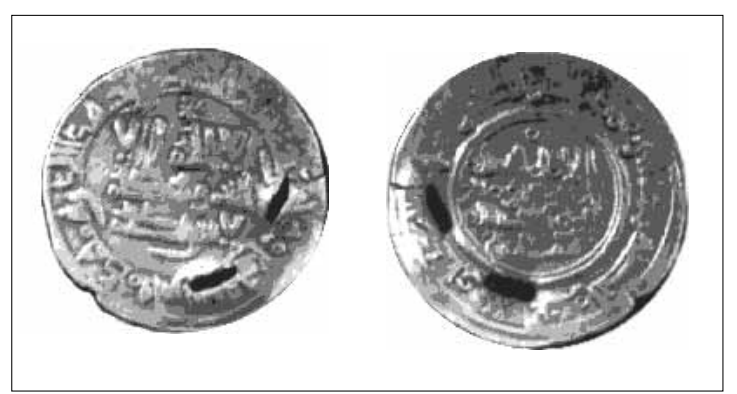

Lám. 4. Catálogo n89 [V.457/M.248.a]

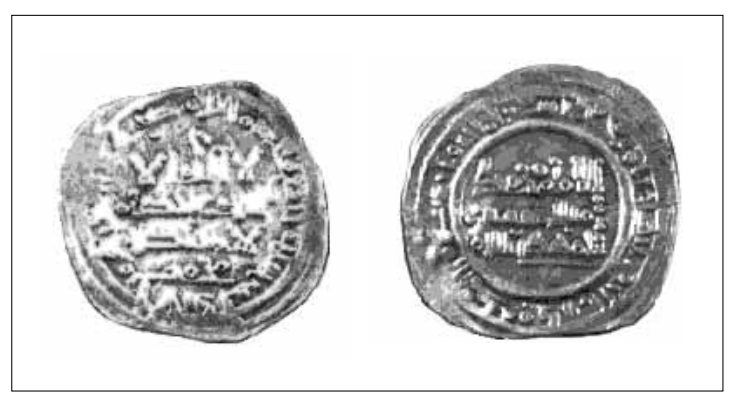

Lám. 6. Catálogo n²06 [V.684/M.342.dd]
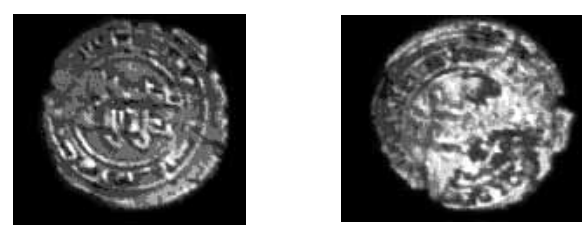

Lám. 8. Catálogo n²41 


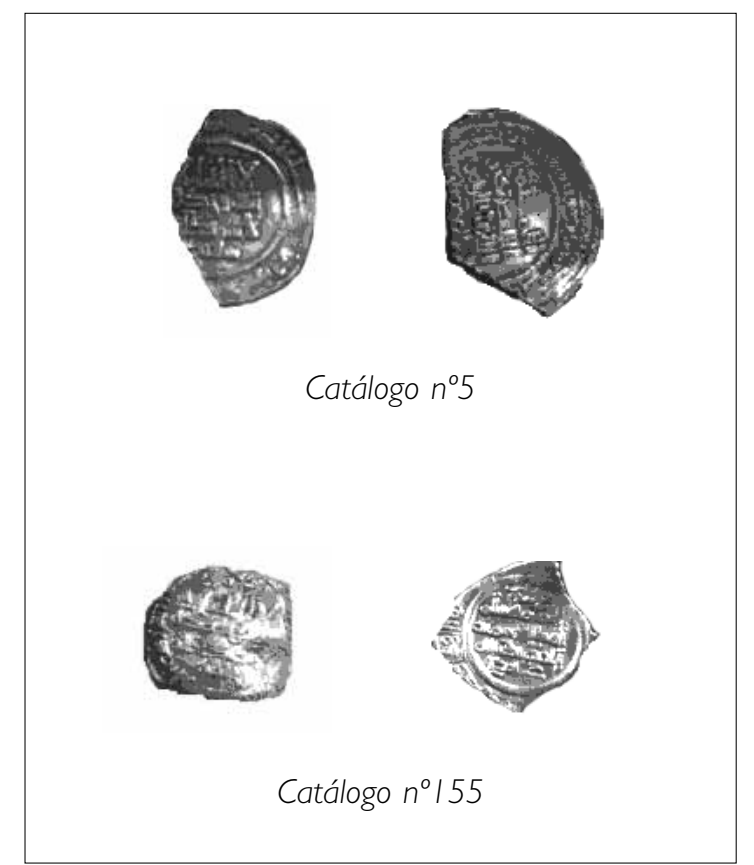

Lám. 9.

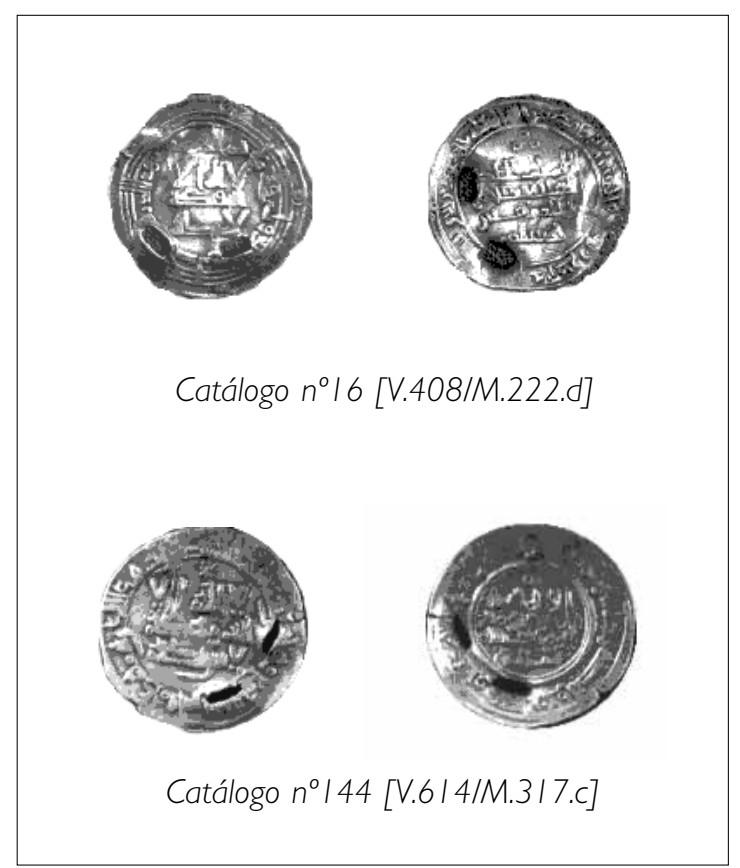

Lám. 10. 